\title{
Synthesis, Characterization, and Agricultural Biological Activities of 5-Fluoro-2-hydroxy Butyrophenone
}

\author{
Fengli Xin, Chunhua Du, Gongjia Lan, and Zhuanping Wu \\ College of Chemistry \& Pharmacy, Qingdao Agricultural University, \\ Research Center of Agricultural Bionic Engineering \& Technology of Shandong Province, Qingdao 266109, China
}

Correspondence should be addressed to Chunhua Du; dch1218@163.com

Received 17 March 2013; Revised 6 May 2013; Accepted 13 May 2013

Academic Editor: Stojan Stavber

Copyright (C) 2013 Fengli Xin et al. This is an open access article distributed under the Creative Commons Attribution License, which permits unrestricted use, distribution, and reproduction in any medium, provided the original work is properly cited.

A novel synthetic approach towards 5-fluoro-2-hydroxy butyrophenone is reported. Using 4-fluorophenol as a raw material, the processes of etherification protection, Friedel-Crafts acylation and demethylation provide the target compound under mild conditions. The structure was characterized by the melting point and IR, MS, ${ }^{1} \mathrm{H}-\mathrm{NMR}$, and ${ }^{13} \mathrm{C}-\mathrm{NMR}$ spectroscopy. The bioassay results indicate that the target compound exhibits potent antifungal activities against Valsa mali, Coniella dipodiella, and other agricultural plant fungi. The target compound also shows potent herbicidal activities for Lactuca sativa, a dicotyledon, and Echinochloa crusgalli, a monocotyledon. The toxicity regression $\mathrm{C}_{50}$ values of the compound against Valsa mali, Coniothyrium diplodiella, Lactuca sativa seedling, and Echinochloa crusgalli seedling were calculated by SPSS. The Hormesis effect for roots of Echinochloa crusgalli was confirmed.

\section{Introduction}

As one of the most important classes of allelochemicals, phenols show wide biological activity to living organisms $[1,2]$. Because of their natural occurrence, biological activity, and industrial applications, extensive attention has been paid to prepare new derivatives by chemical modification and to explore the new application of phenols. For example, the Research Center of Agricultural Bionic Engineering \& Technology of Shandong Province found that 2-hydroxyphenyl-1butanone, that is, 2-(1-butanoyl) phenol can effectively control Valsa mali, Coniella diplodiella, (Speg.) and other plant pathogenic fungi and thus carried out further research into developing a new fungicide [3].

Some special features, such as electronic effect, block effect, mimic effect, and lipid permeability effect, usually make fluorine-containing agricultural chemicals highly effective against pests, weeds, and fungi, and they have been attracting researchers from all over the world [4-6]. Until now, it has not been possible to accurately predict the bioactivity change when substituting atoms with a fluorine-containing group. More experimental research is needed to confirm how and where to introduce fluorine-containing atoms to maximize their impact.
The principal objective of this research is to prepare 5fluoro-2-hydroxy butyrophenone, that is, 4-fluoro-2-butanoyl phenol, and investigate its agricultural biological activities. To the authors' knowledge, the agricultural bioassay of 5-fluoro-2-hydroxy butyrophenone has not been reported so far. Few papers have been published on the preparation of 5fluoro-2-hydroxy butyrophenone, as well as its identification spectra.

The target compound is classified as 2-hydroxy-phenyl ketones which are usually prepared by a Fries rearrangement reaction of a phenolic ester, an intermediate obtained by hydroxyl acylation of a phenol [7]. The strong electron withdrawing of the fluorine atom makes it difficult to change 4fluoro phenolic ester to 5-fluoro-2-hydroxyphenyl ketone. In Suter et al.s paper [8], the target compound was prepared by the Fries rearrangement reaction at $150^{\circ} \mathrm{C}$, with aluminium trichloride existing as a catalyst. Kindler and Oelschläger [9] synthesized the compound at $150^{\circ} \mathrm{C}$, taking 4-fluorine phenol and n-butanoic acid as raw materials, and boron trifluoride as a catalyst. Both methods require a high reaction temperature, and the latter needs a costly boron trifluoride.

In this study, 5-fluoro-2-hydroxy butyrophenone was prepared from the starting material 4-fluorophenol, by the sequential reactions of hydroxyl protection, acylation, and final 


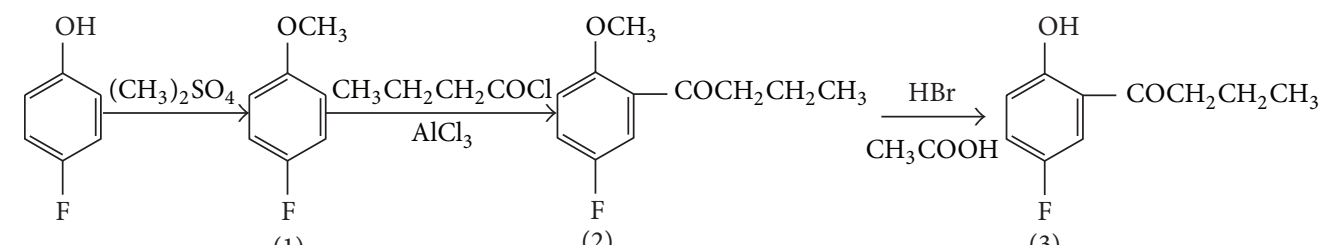

(1)

(2)

(3)

Scheme 1: Synthetic route of 5-fluoro-2-hydroxy butyrophenone.

demethylation to overcome the disadvantages previously mentioned. Scheme 1 shows the experimental synthesis route. Taking cost factors into consideration, 4-fluoroanisole should be manufactured by other more effective route or bought from the marketplace. It can be directly used as the starting material in future production of 5-fluoro-2-hydroxy butyrophenone on an industrial scale. The synthetic route may be referenced by other studies into the preparation of carbonyl phenols $\mathrm{p}$-substituted by a strong electron-withdrawing group.

\section{Experimental}

2.1. Materials and Instrumentation. Anhydrous aluminium trichloride, 4-fluorophenol, dimethyl sulfate, n-butyryl chloride, hydrobromic acid, and other reagent-grade chemicals were commercially available and were used without further purification. Cyprodinil (Syngenta, 50\% WDG) and Pyrazosulfuron-ethyl (Shenzhen Sunrising Industry Co., Ltd, $10 \% \mathrm{WP}$ ) were used as reference fungicide and herbicide, respectively.

Valsa mali and Coniothyrium diplodiella were obtained from the Research Center of Agricultural Bionic Engineering \& Technology of Shandong Province. Lactuca sativa, with the brand of Lisheng, was bought from a seed firm. Echinochloa crusgalli was collected from the campus of Qingdao Agricultural University which was not contaminated by any herbicides. The fungi and plant material specimen has been deposited in the Research Center of Agricultural Bionic Engineering \& Technology of Shandong Province.

${ }^{1} \mathrm{H}-\mathrm{NMR}$ and ${ }^{13} \mathrm{C}-\mathrm{NMR}$ spectra were recorded on a Bruker AV-500 spectrometer. Chemical shifts were reported in ppm relative to tetramethylsilane (TMS), and multiplicities are given as s (singlet), $\mathrm{d}$ (doublet), $\mathrm{t}$ (triplet), $\mathrm{q}$ (quartet), or $\mathrm{m}$ (multiplet). The solvent for NMR spectra was $\mathrm{CDCl}_{3}$. MS spectrum was determined by a Bruker ESI spectrometer, and signals were given in $\mathrm{m} / \mathrm{z}$. IR spectra were investigated by $\mathrm{KBr}$ pellet method for solid sample or liquid film method for liquid sample and recorded in the range of $450-4000 \mathrm{~cm}^{-1}$ by Fourier transform infrared (FTIR) spectroscopy. Melting point was obtained on a WRS-1A numeral melting point apparatus.

\subsection{Synthesis}

2.2.1. 4-Fluoroanisole (1). To a toluene solution (30 mL) of 4fluorophenol (22.4 g, $0.2 \mathrm{~mol}$ ) was added an aqueous solution $(50 \mathrm{~mL}, 15 \%)$ of sodium hydroxide. The reaction mixture was stirred at $10 \sim 20^{\circ} \mathrm{C}$ for $0.5 \mathrm{~h}$. To the mixture, dimethyl sulfate
$(24.62 \mathrm{~mL}, 0.26 \mathrm{~mol})$ was added dropwise in $2 \mathrm{~h}$. The mixture was heated to $40^{\circ} \mathrm{C}$, stirred at the same temperature for $2 \mathrm{~h}$, and then cooled to room temperature. The water phase was extracted with ethyl acetate $(10 \mathrm{~mL} \times 3)$. The combined organic phase was washed with water $(20 \mathrm{~mL} \times 2)$, dried by anhydrous sodium sulfate, and evaporated at $45^{\circ} \mathrm{C}$ under vacuum to provide 1 , as a lightly yellow liquid $(22.83 \mathrm{~g}$ ), in $90.59 \%$ yield. Using a thin plate of silicate gel GF 254 and petroleum ether-ethyl acetate system $(7: 1$, by volume) as a developing agent, RF values of 0.22 and 0.657 were obtained for 4-fluorophenol and $\mathbf{1}$, respectively.

2.2.2. 5-Fluoro-2-methoxy Butyrophenone (2). Under anhydrous conditions, the mixture of n-butyryl chloride $(15 \mathrm{~mL})$ and anhydrous aluminium trichloride $(44.06 \mathrm{~g}, 0.33 \mathrm{~mol}$ ) in carbon disulfide $(90 \mathrm{~mL})$ was stirred for $1 \mathrm{~h}, \mathbf{1}(13.86 \mathrm{~g}$, $0.11 \mathrm{~mol}$ ) was introduced dropwise in $2 \mathrm{~h}$ at $0^{\circ} \mathrm{C}$. Then reaction mixture was stirred for $4 \mathrm{~h}$ at $50^{\circ} \mathrm{C}$. After solvent evaporation under reduced pressure, the residue was treated with $4 \% \sim 6 \%$ hydrochloric acid solution, extracted with benzene $(10 \mathrm{~mL} \times 3)$, and the organic phase obtained was washed with water $(20 \mathrm{~mL} \times 2)$, dried with anhydrous sodium sulfate, and distilled under reduced pressure to give $2(12.75 \mathrm{~g})$, as a slightly yellow liquid, in $59.14 \%$ yield. TLC analysis was performed upon a thin plate of silicate gel GF 254, and the Rf values for 1 and 2 were found to be 0.657 and 0.760 , respectively according to the developing agent of petroleum ether-ethyl acetate system ( $7: 1$, by volume).

2.2.3. 5-Fluoro-2-hydroxy Butyrophenone (3). To a mixture of $2(11.76 \mathrm{~g}, 0.06 \mathrm{~mol})$ and glacial acetic acid $(40 \mathrm{~mL})$ was added hydrobromic acid dropwise $(15 \mathrm{~mL})$ at refluxing temperature; then, the resulting mixture was refluxed for $10 \mathrm{~h}$. The reaction mixture was treated with slight excess of a dilute sodium hydroxide; then, the $\mathrm{pH}$ value was adjusted to $3 \sim 4$ with $10 \% \sim 15 \%$ sulfuric acid solution. This mixture was cooled by the ice-water bath to afford 3 as a slightly yellow crystalline in $61.72 \%$ yield. TLC analysis was carried out by a thin plate of silicate gel GF 254, and the Rf values for $\mathbf{2}$ and $\mathbf{3}$ were found to be 0.760 and 0.561 , respectively, using the developing agent, of petroleum ether-ethyl acetate system ( $7: 1$, by volume).

\subsection{Bioassays}

2.3.1. Antifungal Assay. The mycelium growth rate test [10] was used to investigate the inhibition effects of 5-fluoro2-hydroxy butyrophenone on six popular plant pathogenic fungi. The in vitro test was contacted in Petri dishes, $6.0 \mathrm{~cm}$ in diameter. 5-fluoro-2-hydroxy butyrophenone was dissolved 
in acetone and added to PDA medium (potato $200 \mathrm{~g}$, dextrose $20 \mathrm{~g}$, and agar $17 \mathrm{~g}$ litre $^{-1}$ ) immediately before it was poured into the Petri dishes at $40-45^{\circ} \mathrm{C}$. Compound 3 was tested at $100,50,25,12.5$ and $6.25 \mathrm{mg} \cdot \mathrm{L}^{-1}$ against Valsa mali but at the double doses against Coniothyrium diplodiella. Three replicate plates were used at each concentration. The control received the same quantity of acetone mixed with $\mathrm{PDA}$. The disks of mycelia felt ( $4 \mathrm{~mm}$ diameter) of the pathogenic fungi taken from 7-day-old cultures on PDA plates were inoculated aseptically to the center of Petri dishes. The treatments were incubated at $25^{\circ} \mathrm{C}$. Colony growth diameter was measured when the fungal growth in the control treatments had just completely covered or was about to cover the Petri dishes. Antifungal activity was expressed in terms of percentage of mycelium growth inhibition calculated from the following formula:

$$
\text { mycelium growth inhibition }=\left[\frac{\left(d_{c}-d_{t}\right)}{\left(d_{c}-4\right)}\right] \times 100,
$$

where $d_{c}$ and $d_{t}$ are average diameters in mm of fungal colonies of control and treatment, respectively.

The multiple compare of the inhibition of the test compound against various fungi was carried out by Duncan's method with statistical analysis software-SPSS 15.0. The $\mathrm{EC}_{50}$ values were estimated with the same software based on probit analysis.

2.3.2. Herbicidal Assay. The herbicidal activity of 5-fluoro2-hydroxy butyrophenone was evaluated using a previously reported procedure [11]. The receptor plants' seeds were sterilized with $2 \%$ sodium hypochlorite solution for 15 minutes, washed with distilled water, dipped in running tap water for $5 \mathrm{~h}$ was placed on the moistened papers, and then put into a plant incubator for germination. The acrospire was allowed to grow to 2-3 $\mathrm{mm}$, before it was inserted into a PPA medium (agar $5 \mathrm{~g} \cdot \mathrm{L}^{-1}$ ). Stock solution of 5-fluoro-2-hydroxy butyrophenone was prepared in acetone at a concentration of $50000 \mathrm{mg} \cdot \mathrm{L}^{-1}$ and then diluted to the required test concentrations. Three replicate cups were used at each concentration. The control received the same quantity of acetone mixed with PPA.

The sprouting seeds were planted into the PPA medium in a cup of $25 \mathrm{~mL}$. The treatments were maintained at a plant incubator for $2-5$ days, at $25^{\circ} \mathrm{C}$ and relative humidity $60 \%$. The root length and hypocotyl length were measured when the root was about to touch the cup bottom. The herbicidal activity on test weeds was evaluated by the inhibition rate calculated as follows:

$$
\begin{aligned}
& \text { root growth inhibition }=\frac{\left(L_{c}-L_{t}\right)}{\left(L_{c}-2\right)} \times 100, \\
& \text { hypocotyl growth inhibition }=\frac{\left(L_{c}-L_{t}\right)}{L_{c} \times 100},
\end{aligned}
$$

where $L_{c}$ and $L_{t}$ are average diameters in $\mathrm{mm}$ of root length or hypocotyl length of control and treatment, respectively.

The $\mathrm{EC}_{50}$ values were calculated using SPSS 15.0 based on probit analysis.

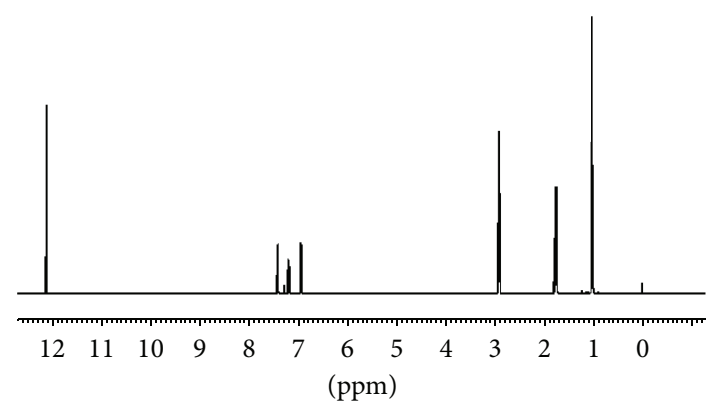

FIGURE 1: ${ }^{1}$ H-NMR spectra of 5-fluoro-2-hydroxy butyrophenone.

\section{Results and Discussion}

\subsection{Characterization of Compounds}

3.1.1. 4-Fluoroanisole (Compound 1). IR $\left(\mathrm{KBr}, \bar{v}, \mathrm{~cm}^{-1}\right): 3076$ $(v: \mathrm{Ar} \mathrm{C}-\mathrm{H}), 2966\left(v_{\mathrm{as}:-\mathrm{CH} 3}\right), 1604\left(v: \mathrm{Ar}_{\mathrm{C}=\mathrm{C}}\right), 1153\left(v_{\mathrm{as}: \mathrm{C}-\mathrm{F}}\right)$, $1036\left(v_{\mathrm{C}-\mathrm{F}}\right)$, and $830\left(\gamma: \mathrm{Ar}_{\mathrm{C}-\mathrm{H}}\right.$, assigned to 1,4-disubstituted phenol ring). ${ }^{1} \mathrm{H}-\mathrm{NMR}\left(500 \mathrm{MHz}, \mathrm{CDCl}_{3}\right), \delta$ (ppm): 6.96 $7.01(2 \mathrm{H}, \mathrm{m}, \mathrm{Ar}-\mathrm{H}), 6.81 \sim 6.88(2 \mathrm{H}, \mathrm{m}, \mathrm{Ar}-\mathrm{H}), 3.78(3 \mathrm{H}, \mathrm{s}$, $\mathrm{CH}_{3}$ ).

3.1.2. Preparation of 5-Fluoro-2-methoxy Butyrophenone (Compound 2). IR (KBr, $\left.\bar{v}, \mathrm{~cm}^{-1}\right): 2971(v$ : Ar C-H), 2941 $\left(v_{\text {as:-CH3 }}\right), 1715\left(v_{: \mathrm{C}=\mathrm{O}}\right), 1220\left(v_{\text {as:C-O-C }}\right), 1096\left(v_{\text {as:C}-\mathrm{F}}\right), 1040$ $\left(v_{: \mathrm{C}-\mathrm{F}}\right)$, and $832\left(\gamma: \mathrm{Ar}_{\mathrm{C}-\mathrm{H}}\right.$, assigned to 1,2,4-trisubstituted phenyl). ${ }^{1} \mathrm{H}-\mathrm{NMR}\left(500 \mathrm{MHz}, \mathrm{CDCl}_{3}\right), \delta$ (ppm): 7.52 7.55 (1H, dd, Ar-H), $7.22 \sim 7.26(1 \mathrm{H}, \mathrm{m}, \mathrm{Ar}-\mathrm{H}), 6.97 \sim 7.02(1 \mathrm{H}, \mathrm{dd}$, $\mathrm{Ar}-\mathrm{H}), 3.78\left(3 \mathrm{H}, \mathrm{s}, \mathrm{CH}_{3}\right), 2.92 \sim 2.94\left(2 \mathrm{H}, \mathrm{t},-\mathrm{CO}-\mathrm{CH}_{2}-\right)$, $1.75 \sim 1.82\left(2 \mathrm{H}, \mathrm{m},-\mathrm{CH}_{2}-\right)$, 1.01 1.04 $\left(3 \mathrm{H}, \mathrm{t},-\mathrm{CH}_{3}\right)$.

3.1.3. 5-Fluoro-2-hydroxy Butyrophenone (Compound 3). The melting Point was $37.8 \sim 38.3^{\circ} \mathrm{C}$, which is in good agreement with $38 \sim 39^{\circ} \mathrm{C}$ reported in research papers $[8,9]$. IR $(\mathrm{KBr}, \bar{v}$, $\left.\mathrm{cm}^{-1}\right)$ : $3444\left(v_{: \mathrm{OH}}\right), 2968\left(v_{\text {as:-CH3 }}\right), 1650\left(v_{: \mathrm{C}=\mathrm{O}} ; v: \mathrm{Ar}_{\mathrm{C}=\mathrm{C}}\right)$, $1585\left(v: \operatorname{Ar}_{\mathrm{C}=\mathrm{C}}\right), 1488\left(v: \operatorname{Ar}_{\mathrm{C}=\mathrm{C}}\right), 1384\left(v_{\mathrm{as}:-\mathrm{CH} 3}\right), 1130\left(v_{\mathrm{as}: \mathrm{C}-\mathrm{F}}\right)$, $994\left(v_{: \mathrm{C}-\mathrm{F}}\right)$, and $857\left(\gamma: \mathrm{Ar}_{\mathrm{C}-\mathrm{H}}\right.$, assigned to 1,2,4-trisustituted phenol ring). ESI-MS, $\mathrm{M}^{+}: \mathrm{m} / \mathrm{z}$ 183.0. ${ }^{1} \mathrm{H}-\mathrm{NMR}(500 \mathrm{MHz}$, $\left.\mathrm{CDCl}_{3}\right), \delta$ (ppm): $12.12(1 \mathrm{H}, \mathrm{s}, \mathrm{Ar}-\mathrm{OH}$, forming intramolecular hydrogen bond with ortho-position $\mathrm{C}=\mathrm{O}), 7.41 \sim 7.43(1 \mathrm{H}$, $\mathrm{dd}, \mathrm{Ar}-\mathrm{H}), 7.18 \sim 7.22(1 \mathrm{H}, \mathrm{m}, \mathrm{Ar}-\mathrm{H}), 6.93 \sim 6.96(1 \mathrm{H}, \mathrm{dd}$, $\mathrm{Ar}-\mathrm{H}), 2.91 \sim 2.94\left(2 \mathrm{H}, \mathrm{t},-\mathrm{CO}-\mathrm{CH}_{2}-\right), 1.74 \sim 1.82(2 \mathrm{H}, \mathrm{m}$, $\left.-\mathrm{CH}_{2}-\right)$, and 1.01 1.05 (3H, t, $\left.-\mathrm{CH}_{3}\right) .{ }^{13} \mathrm{C}-\mathrm{NMR}(500 \mathrm{MHz}$, $\left.\mathrm{CDCl}_{3}\right), \delta(\mathrm{ppm})$ : seven signal peaks in the low field regions, 205.84 (C=O), 158.66 (Ar), 155.73 (Ar), 123.64 123.84 (d, Ar), 119.76 119.82 (d, Ar), 118.79 118.84 (d, Ar), and 114.76 114.95 (d, Ar); three signal peaks were found in the high field regions, $40.27\left(-\mathrm{CH}_{2}-\right), 17.68\left(-\mathrm{CH}_{2}-\right)$, and $13.75\left(\mathrm{CH}_{3}\right)$. The spectra of ${ }^{1} \mathrm{H}-\mathrm{NMR}$ and ${ }^{13} \mathrm{C}-\mathrm{NMR}$ are shown in Figures 1 and 2 , respectively.

The yield of the final target compound is $33.1 \%$ in our mild synthesis route, which is lower than that of Fires rearrangement approach at $150^{\circ} \mathrm{C}(70.6 \%)$ [8] and that of catalytic method using costly boron trifluoride (79.7\%) [9]. The ideal preparation method needs continual investigating. We will report the related research in another paper. 


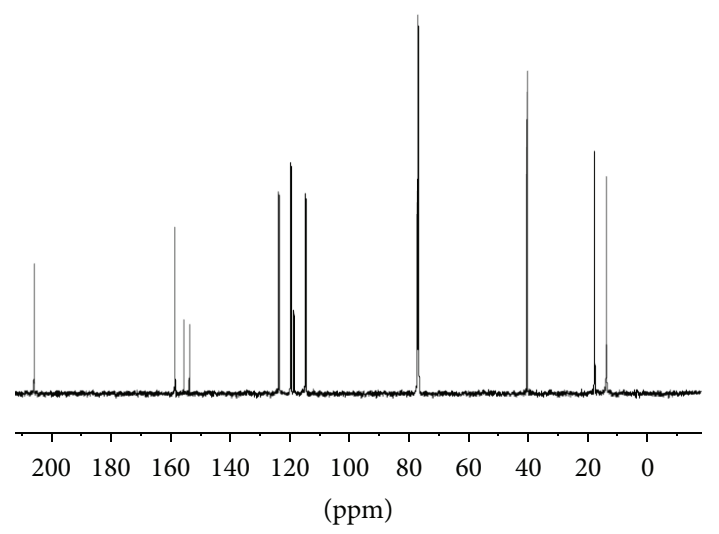

FIgURE 2: ${ }^{13} \mathrm{C}$-NMR spectra of 5-fluoro-2-hydroxy butyrophenone.

TABLE 1: Antifungal activity of 5-fluoro-2-hydroxy butyrophenone against six plant pathogenic fungi.

\begin{tabular}{lc}
\hline Fungus & $\begin{array}{c}\text { Mycelial growth } \\
\text { inhibition }(\%)^{\#}\end{array}$ \\
\hline Fusarium graminearum Sehw & $41.6^{\mathrm{c}}$ \\
Valsa mali & $79.0^{\mathrm{a}}$ \\
Fusarium oxysporum f. vasinfectum & $25.0^{\mathrm{f}}$ \\
Coniella diplodiella & $66.0^{\mathrm{b}}$ \\
Fusarium oxysporum f. sp. cucumerinum & $36.6^{\mathrm{d}}$ \\
Alternaria brassicae & $27.9^{\mathrm{e}}$ \\
\hline
\end{tabular}

${ }^{\#}$ Mycelial growth inhibition percentages within a column followed by the same letter are not significantly different $(P<0.05)$.

\subsection{Agricultural Biological Activities of Compound $\mathbf{3}$}

3.2.1. Antifungal Activity against Six Plant Pathogenic Fungi. Compound $\mathbf{3}$ was tested for its antifungal activity against six fungi species at $100 \mathrm{mg}$ litre $^{-1}$. Table 1 shows that the compound exhibits antifungal activity against the test fungi with different sensitivities. It also shows the strongest activity against Valsa mali and Coniella diplodiella and the lowest antifungal activity against Fusarium oxysporum $f$. Sp. vasinfectum and Alternaria brassicae.

As shown in Table 2, 5-fluoro-2-hydroxy butyrophenone displays good fungicidal activity against Valsa mali and Coniothyrium diplodiella, and the $\mathrm{EC}_{50}$ values were 31.46 and $58.62 \mathrm{mg} \cdot \mathrm{L}^{-1}$, respectively. The antifungal activity of the compound against Valsa mali and Coniothyrium diplodiella is weaker than that of Cyprodinil, which showed $\mathrm{EC}_{50}$ values of 10.4 and $10.2 \mathrm{mg} \cdot \mathrm{L}^{-1}$, respectively.

3.2.2. Inhibition against the Seedling of 2 Plants. The growth inhibition was clearly observed on the roots and hypocotyls of Lactuca sativa seedlings at the concentration of 15.625 $\mathrm{mg} \cdot \mathrm{L}^{-1}$. As shown in Figure 3, the lengths of both roots and hypocotyls decreased as the concentration increased.

As seen from Figure 4, the inhibition was evident on hypocotyls of Echinochloa crusgalli at the concentrations of compound 3 from $15 \mathrm{mg} \cdot \mathrm{L}^{-1}$ to $240 \mathrm{mg} \cdot \mathrm{L}^{-1}$ and the instances



Figure 3: Bioassay of 5-fluoro-2-hydroxy butyrophenone on the seedling growth of Lactuca sativa $\mathrm{L}$.

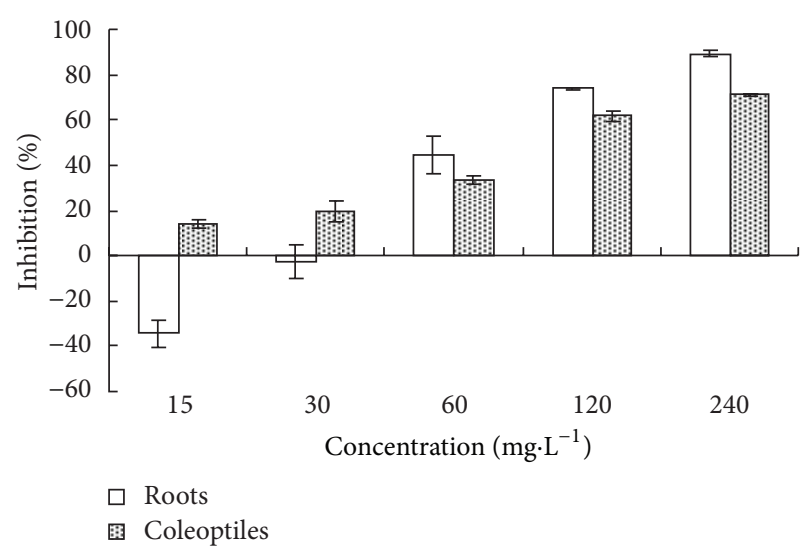

Figure 4: Bioassay of 5-fluoro-2-hydroxy butyrophenone on seedling growth of Echinochloa crusgalli.

of low promote and high restrain; that is, Hormesis effect for roots of Echinochloa crusgall was confirmed.

Table 3 gives the $\mathrm{EC}_{50}$ values of 5-fluoro-2-hydroxy butyrophenone against the seedling growth of Lactuca sativa and Echinochloa crusgalli. The herbicidal activity of the compound against Echinochloa crusgalli is weaker than that of Pyrazosulfuron-ethyl, which showed $\mathrm{EC}_{50}$ value of 7.18 $\mathrm{mg} \cdot \mathrm{L}^{-1}$ for the hypocotyls inhibition.

3.2.3. Discussion on the Agricultural Application. The data presented in Tables 1-3 and in Figures 3-4 indicate that 5fluoro-2-hydroxy butyrophenone is effective in controlling fungus growth and inhibiting plant growth. It should be noted that the test plants, Lactuca sativa and Echinochloa crusgalli, belong to dicotyledons and monocotyledons, respectively. This means that 5-fluoro-2-hydroxy butyrophenone may have a broad-spectrum activity. There is a potential to develop 5-fluoro-2-hydroxy butyrophenone as a herbicide or an agricultural regulator with good antifungal activity. 5-Fluoro-2hydroxy butyrophenone can also be considered as a leading compound in devising new fungicides, herbicides, or plant regulators. 
TABle 2: Antifungal activities of 5-fluoro-2-hydroxy butyrophenone against two pathogenetic fungi.

\begin{tabular}{lccc}
\hline Pathogenetic fungi & Toxicity regression equation ${ }^{\mathrm{a}}$ & $\mathrm{EC}_{50}^{\mathrm{b}} / \mathrm{mg}^{\mathrm{L}} \mathrm{L}^{-1}(95 \%$ confidence interval $)$ & $\mathrm{Chi}^{- \text {square }^{\mathrm{c}}}$ \\
\hline Valsa mali & $Y=-2.426+1.617 X$ & $31.46(26.53-37.74)$ & 0.652 \\
Coniothyrium diplodiella & $Y=-3.957+2.238 X$ & $58.62(51.38-67.16)$ & 0.675 \\
\hline
\end{tabular}

${ }^{\text {a }}$ PROBIT model: $Y$ (probit) $=$ intercept $+B X$ (covariates $X$ are transformed using the base 10 logarithm).

${ }^{\mathrm{b}}$ Cyprodinil displayed better fungicidal activity against Valsa mali and Coniothyrium diplodiella, with the $\mathrm{EC}_{50}$ values being 10.4 and $10.2 \mathrm{mg} \cdot \mathrm{L}^{-1}$, respectively. ${ }^{c} \chi^{2}<\chi_{(3,0.05)}^{2}=7.815$ shows that toxicity regression equations obtained can be used for predictions of the inhibition effects.

TABLE 3: Inhibition of 5-fluoro-2-hydroxy butyrophenone on the seedlings growth of two plants.

\begin{tabular}{|c|c|c|c|}
\hline Receptor plant species & Toxicity regression equation $^{\mathrm{a}}$ & $\mathrm{EC}_{50}^{\mathrm{b}} / \mathrm{mg} \cdot \mathrm{L}^{-1}(95 \%$ confidence interval $)$ & Chi-square $^{c}$ \\
\hline \multicolumn{4}{|l|}{ Lactuca sativa } \\
\hline Roots & $Y=-3.379+1.732 X$ & $89.36(75.98-106.64)$ & 2.147 \\
\hline Hypocotyls & $Y=-2.003+1.096 X$ & $67.25(52.66-86.58)$ & 0.501 \\
\hline \multicolumn{4}{|l|}{ Echinochloa crusgalli } \\
\hline Roots & d & $\mathrm{d}$ & d \\
\hline Hypocotyls & $Y=-2.967+1.477 X$ & $102.20(84.56-127.32)$ & 3.933 \\
\hline
\end{tabular}

${ }^{\text {a }}$ PROBIT model: $Y$ (probit) $=$ intercept $+B X$ (covariates $X$ are transformed using the base 10 logarithm).

${ }^{\mathrm{b}}$ Pyrazosulfuron-ethyl displayed better herbicidal activity against Echinochloa crusgalli, with the $\mathrm{EC}_{50}$ value of $7.18 \mathrm{mg} \cdot \mathrm{L}^{-1}$ for the hypocotyls inhibition.

${ }^{c} \chi^{2}<\chi_{(3,0.05)}^{2}=7.815$ shows that toxicity regression equations obtained can be used for predictions of the inhibition effects.

${ }^{\mathrm{d}}$ Because of Hormesis effect, no calculation was done.

\section{Conclusions}

In summary, 5-fluoro-2-hydroxy butyrophenone was synthesized under mild conditions, and the structure was characterized by the melting point and MS, IR, ${ }^{1} \mathrm{H}$ NMR, and ${ }^{13} \mathrm{C}$ NMR spectroscopy. The bioassay results show that it exhibits potent capabilities against Valsa mali, Coniella dipodiella, and other agricultural plant fungi. It also inhibits the growth of Lactuca sativa, a dicotyledon, and Echinochloa crusgalli, a monocotyledon. Hormesis effect for roots of Echinochloa crusgal was found. There is a potential to develop 5-fluoro-2hydroxy butyrophenone as an agricultural regulator or herbicide with good antifungal activity or as a leading compound in creating new fungicides, herbicides, or plant regulators.

\section{Conflict of Interests}

This paper is the authors' own work, and the research is original. The results have not been published (in any language or medium), and the paper is not considered and will not be offered elsewhere while under consideration for the Journal of Chemistry. All authors have read and approved the revised version of the paper, and due care has been taken to ensure the integrity of the work. No conflict of interest exists in the submission of the revised version. There is no any other possible conflict of interests in the revised version.

\section{Acknowledgments}

The authors gratefully acknowledge the financial supports from Scientific Research Program of the Higher Education Institution of Shandong Province (no. J11LC21) and Promotive Research Fund for Young and Middle-aged Scientists of Shandong Province (no. KCCX1-SW-22).

\section{References}

[1] O. Tsutomu, "Oxidation of phenolic acid derivatives by soil and its relevance to allelopathic activity," Journal of Environmental Quality, vol. 30, no. 5, pp. 1631-1635, 2001.

[2] A. M. Rimando, M. Olofsdotter, F. E. Dayan, and S. O. Duke, "Searching for rice allelochemicals: an example of bioassayguided isolation," Agronomy Journal, vol. 93, no. 1, pp. 16-20, 2001.

[3] Z. L. Meng, B. H. Qu, J. Shang et al., "Synthesis of o-droxybutyrophenone and p-Hydroxybutyrophenone," CN 1490295A, 2004-04-21.

[4] C. H. Du, W. Y. Zhang, and P. Peng, "Special functions and creation of fluorine-containing biologically active molecules," Fine and Specialty Chemicals, vol. 15, pp. 15-18, 2007 (Chinese).

[5] J. McCarthy, "Utility of fluorine in biological active molecules, division of fluorine chemistry tutorial. San Francisco," in Proceedings of the 219th National Meeting of American Chemical Society, March 2000.

[6] B. E. Smart, "Fluorine substituent effects (on bioactivity)," Journal of Fluorine Chemistry, vol. 109, pp. 3-11, 2001.

[7] R. L. Sheng, Y. X. Yang, J. P. Zhang et al., "One pot synthesis of 5-fluoro-2-hydroxy-hypnone," Chinese Journal of Synthetic Chemistry, vol. 13, pp. 186-188, 2005.

[8] C. M. Suter, E. J. Lawson, and P. G. Smith, "The synthesis and germicidal properties of some alkylfluorophenols," Journal of the American Chemical Society, vol. 61, no. 1, pp. 161-165, 1939.

[9] K. Kindler and H. Oelschläger, "Studien über den mechanismus chemischer Reaktionen, XV. Mitteil: Über die synthesis von halogenierten acylphenolen mittels freier carbonsäuren," Chemische Berichte, vol. 87, no. 2, pp. 194-202, 1954.

[10] X. H. Li, X. L. Yang, Y. Ling et al., "Synthesis and fungicidal activity of novel 2-oxocycloalkylsulfonylureas," Journal of Agricultural and Food Chemistry, vol. 53, no. 6, pp. 2202-2206, 2005.

[11] X. Y. Luo, Y. H. Fu, and S. J. Zhou, "Establishment and application of PPA method for assessment of the allelopathic activity in plant leaves," Journal of Qingdao Agricultural University, vol. 24, pp. 267-270, 2007. 



\section{Carbohydrate} Chemistry

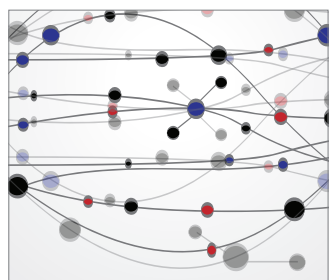

The Scientific World Journal
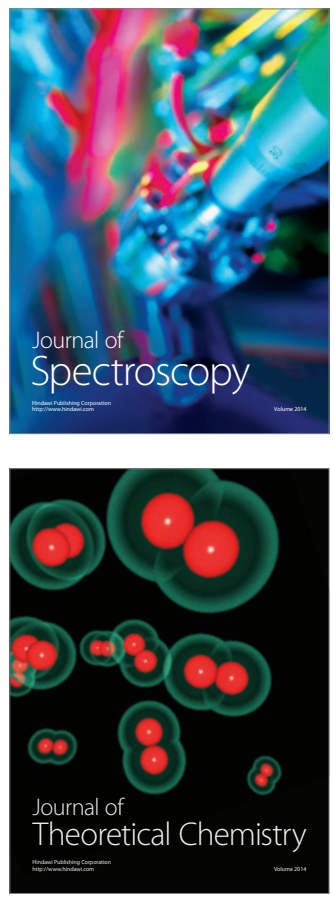
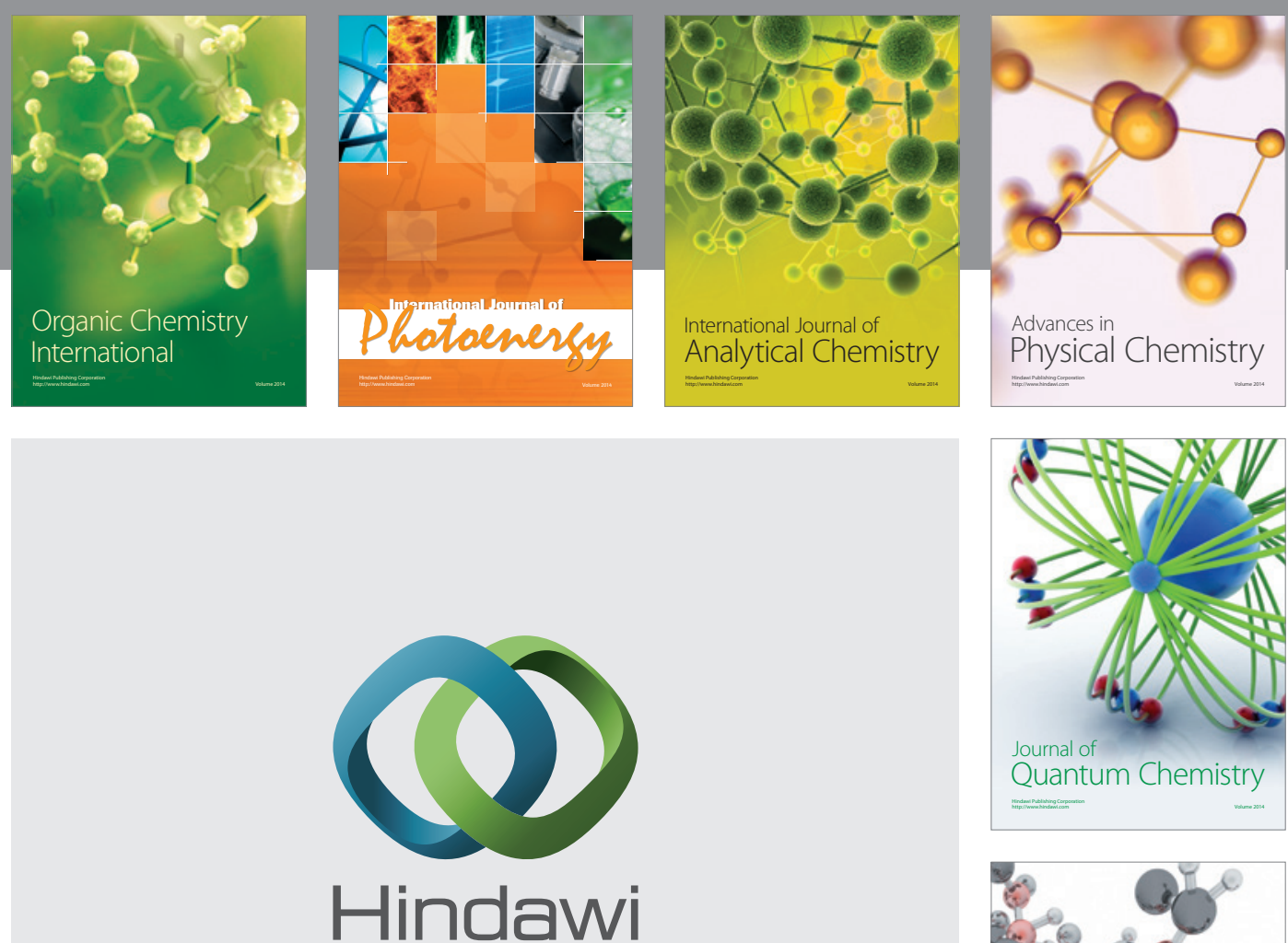

Submit your manuscripts at

http://www.hindawi.com

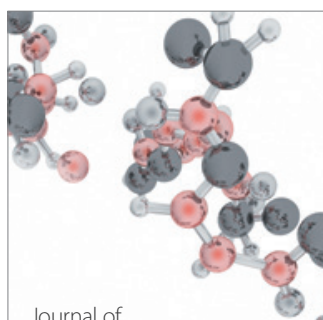

Analytical Methods

in Chemistry

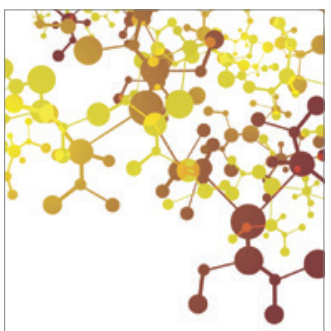

Journal of

Applied Chemistry

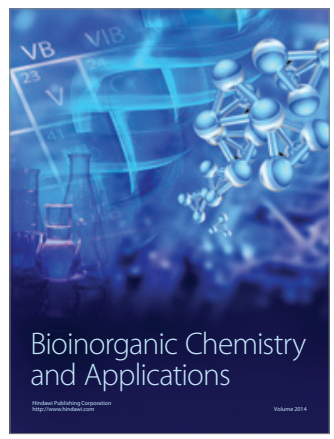

Inorganic Chemistry
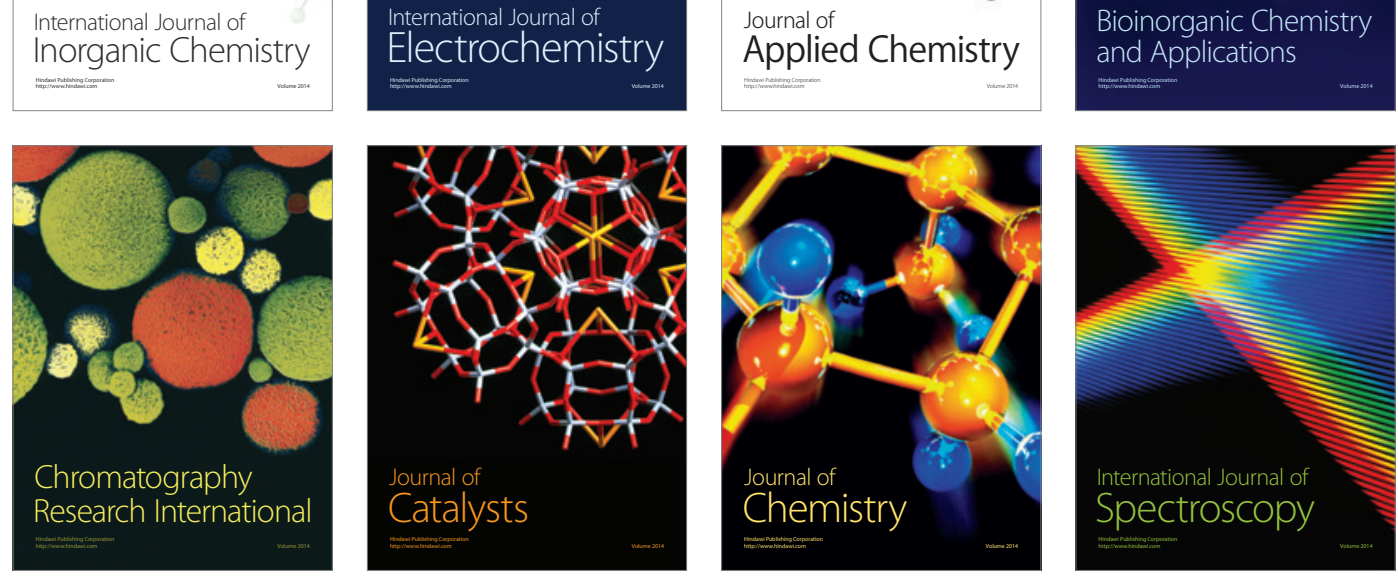